\title{
CULTURA, COTIDIANO QUILOMBOLA E O BRINCAR DE CRIANÇAS RIBEIRINHAS DE ABAETETUBA-PA
}

\author{
Eliana Campos POJO ${ }^{1}$ \\ Universidade Federal do Pará/UFPA \\ elianapojo@ufpa.br \\ Josilene Ferreira BARRETO \\ Graduada de Pedagogia \\ (jlene1@hotmail.com)
}

Resumo: Este texto é parte integrante da pesquisa desenvolvida por meio do projeto de intervenção metodológica denominado Integrando conhecimentos e saberes: uma experiência educativa na primeira escola quilombola de Abaetetuba-PA, desenvolvido pelo Grupo de Estudo, Pesquisa e Extensão, Sociedade, Estado e Educação - GEPESEED, com reflexões que envolvem as seguintes dimensões: cultura quilombola, cotidiano e o brincar de crianças ribeirinhas do rio Baixo-Itacuruçá, nesse município. O objetivo foi discutir a cultura quilombola a partir das brincadeiras das crianças $e$ de seu cotidiano, buscando apreender sentidos e significados quanto à dinâmica cultural e sua importância para a identidade da comunidade. A pesquisa focalizou estudos de cunho etnográfico situando o caráter observativo, participativo, de conhecimento denso da comunidade, por onde perpassamos o acompanhamento

1 Professora da Faculdade de Educação e Ciências Sociais do Campus Universitário de Abaetetuba/UFPA. Doutoranda do programa de Ciências Sociais do IFCH/UNICAMP.

2 Graduada em Pedagogia. Integrante do Grupo de Pesquisa e Extensão GEPESEED. 
das brincadeiras das crianças, a interlocução com conversas junto às crianças e adultos, a produção de oficinas envolvendo as crianças e, ainda, a observação das práticas sociais do lugar, de modo geral. Do processo, observamos que o estudo possibilitou compreender as crianças como agentes produtoras de cultura, como cidadãos que interagem como os diversos meios produtivos, seja via o convívio com os adultos aprendendo, por exemplo, a produção da farinha, o plantio da roça, também na relação com outras crianças ensinando e aprendendo novas brincadeiras e com seus pais trocando experiências cotidianas de modo que demarcam o existir, sendo transformadoras da própria cultura.

Palavras-chave: Cultura Quilombola. Cotidiano. Brincar.

Abstract: This text is part of the research carried out by means of the methodological intervention project called Integrating Knowledge and Learning: an educational experience in the first Maroon school Abaetetuba-PA, developed by Study Group and Research, Society, State and Education - GEPESEED, with reflections involving the following dimensions: maroon culture, everyday life and play riverine children Low - Itacuruçá river, this city. The aim was to discuss the Maroon culture from the games of children and routine, and attempting senses and meanings as cultural dynamics and its importance to the community's identity. The research focused ethnographic studies placing the observational, participatory nature of dense knowledge of the community, where monitoring of children's play, the dialogue with conversations among children and adults, the production of workshops involving children and also observation of social practices of the place in general. We noted that the study allowed understanding children as agents producing culture, as citizens interacting in many productive ways, either by interaction with adults, learning, for example, the production of flour, planting the garden, or in relation with other children and learning new tricks with his parents and changing everyday experiences to focus existence and transforming the culture itself.

Keywords: Quilombo Culture. Everyday. Play.

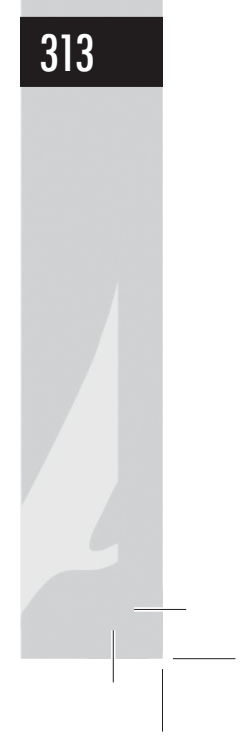




\section{Introdução}

O presente texto resulta da pesquisa e ações de intervenção por meio do Projeto $^{3}$ de intervenção metodológica intitulado Integrando conhecimentos e saberes: uma experiência educativa na primeira escola quilombola de Abaetetuba-PA, como vivência pedagógica e cultural junto à comunidade quilombola (comunidade Nossa Senhora do Perpétuo Socorro), localizada no rio Baixo-Itacuruçá. Tais ações se dirigiam perpassando o aceite e apoio institucional da Escola Santo André ${ }^{4}$, que fica nessa comunidade.

O rio Baixo-Itacuruçá localiza-se na região das ilhas de Abaetetuba. Nele está presente uma comunidade considerada quilombola, legalmente ${ }^{5}$ desde 2002 , como povo remanescente de quilombo, com características manifestas de maneira peculiar no dia a dia através de suas brincadeiras, linguagens, danças, modos de vida, parentesco, do trabalho e, ainda, pela dinâmica social com os rios, igapós, igarapés, matas, florestas e a terra, sedimentando uma interlocução harmoniosa com a natureza.

3 Esse projeto concorreu e foi aprovado pelo Edital no 14/2012 da UFPA. Trata-se de um edital de Programa de Apoio a Projetos de Intervenção Metodológica - PAPIM, é um projeto financiado e tem vigência de um ano (2013), desenvolvido pelo Grupo de Estudo, Pesquisa e Extensão, Sociedade, Estado e Educação - GEPESEED.

4 Trata do projeto intitulado Integrando conhecimentos e saberes: uma experiência educativa na primeira escola quilombola de Abaetetuba.

5 Desde a Constituição Federal de 1988, abriu-se a possibilidade de reconhecimento dos espaços que guardam relação histórica com a escravidão, assegurando-lhes direitos territoriais. O Artigo 68 do Ato das Disposições Constitucionais Transitórias (ADCT) trouxe consigo um aparato legal que procura relacionar comunidades negras contemporâneas, portadoras de determinadas especificidades étnicas, com a experiência histórica dos quilombos, trazendo o seguinte texto constitucional: "Aos remanescentes das comunidades de quilombos que estejam ocupando suas terras é reconhecida a propriedade definitiva, devendo o Estado emitir-lhes títulos respectivos". 
Inferimos como hipótese que as pessoas não estão convencidas da importância identitária para a formação dos sujeitos e, nem a escola valoriza a história e a tradição quilombola como importante para a cidadania e identidade de povo desse lugar, assim como para o respeito à diversidade brasileira. Percebemos que a tradição quilombola é, na maioria das vezes, silenciada no tempo presente e em sua história, principalmente para as crianças que já nascem nessa 'sociedade globalizada', onde o que predomina é a cultura de massa. São esses questionamentos e contrastes que nos propomos trazer à tona nesse escrito, elucidando a identidade cultural da comunidade pesquisada por meio das manifestações culturais representadas pelas crianças através de seus modos de vida, das brincadeiras, do trabalho, das relações com os adultos situando pontos de vista sobre o viver nessa comunidade tradicional e sua dinamicidade cultural.

A opção pelo olhar das crianças foi devida à disposição e modos próprios de elas lidarem com o cotidiano ribeirinho e quilombola manifestadas em suas produções em nível cognitivo, afetivo e social durante as brincadeiras de que participam. Suas infâncias se expressam na dinâmica cultural como sujeitos que residem às margens dos rios, na terra e no convívio com a natureza, nos aprendizados dentro e fora da escola. Desse cotidiano do brincar, buscamos compreender sobre as manifestações culturais presentes na comunidade.

\section{INTERFACE ENTRE CULTURA E COTIDIANO QUILOMBOLA}

O cotidiano dos moradores do rio Baixo-Itacuruçá circunda, entre outras coisas, pelo trabalho na roça, na olaria, no ir até a cidade, nos afazeres de casa, nas programações festivas da igreja e da escola, nas brincadeiras das crianças, no passeio aos domingos na casa de parentes e na participação das atividades religiosas.

As pessoas sobrevivem dos trabalhos em olarias, que são construídas à margem do rio pela facilidade do embarque do barro, da lenha e do escoamento dos produtos produzidos 


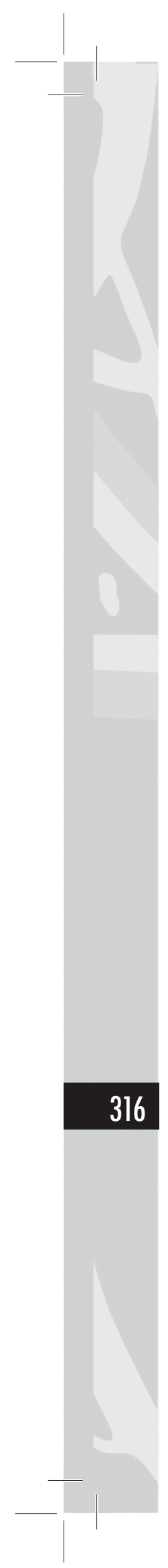

como o tijolo e a telha. Também é presente o cultivo do açaí por conta da terra à beira do rio (várzea) ser mais fértil para esse tipo de plantio, e, em terra firme (onde a maré não alaga), há o cultivo de roça com a plantação de mandioca, macaxeira, milho, arroz que são produtos cultivados para vendas e o consumo das famílias. Outras famílias vivem às margens do rio e trabalham e se alimentam da pesca, esses modos de produção se dão de forma múltipla e simultânea, ou seja, muitas vezes a mesma família trabalha na olaria, produz e tem cultivo na roça e atua com a pesca, de modo que tais atividades são parte do sustento das famílias. Essa afirmação pode ser traduzida na fala do senhor Lucindo, quando trata da relação da farinha como parte da cultura quilombola,

Em Alagoas, que formaram os Quilombos dos Palmares, eles tinham... formaram lá uma comunidade grande e eles tinham as sementes, onde eles plantaram e sobreviveram lá por vários anos. Então nós hoje cultivamos a farinha, a macaxeira, que muitos conhecem pelo aipim. Então hoje a gente cultiva ainda essas coisas. (Morador do rio Baixo-Itacuruçá)

A visão expressa pelo morador sobre a produção da farinha, como forma de produção para sobrevivência, alimentação e comercialização, reproduz também a manutenção da tradição de seus antepassados, na qual observa-se a tradição de costumes dos negros e indígenas no fazer diário dessa comunidade.

Os trabalhos tanto na roça quanto na olaria "demarcam traços de enraizamento cultural e, por conseguinte, de resistência. Resistência pressupõe, aqui, diferença histórica, interna e específica; ritmo próprio; modo peculiar de existir no tempo histórico e no tempo subjetivo". (BOSI apud OLIVEIRA, 2004, p. 37).

Notamos que essa comunidade quilombola e ribeirinha está sob influência de outras culturas, especialmente a cultura de massa que tenta homogeneizar a todos como se não houvesse outras formas de representações culturais, pois se acredita que 
“(...) a cultura nos modelou como espécies únicas e sem dúvida ainda está nos modelando - assim também, ela nos modela como indivíduos separados" (GEERTZ, 1989, p. 64). Nesse sentido não há somente uma maneira de representação cultural, pois cada povo tem um modo próprio de falar, de se alimentar, de se relacionar com seu próximo, de brincar e etc. No dizer de Brandão significa que o

ser o sujeito da história e ser o agente criador da cultura não são adjetivos qualificadores do homem. São o seu substantivo. Mas não são igualmente a sua essência e sim um momento do seu próprio processo de humanização. (2002, p. 41)

Com base nesse pensar, o processo de humanização do homem também é cultura, as suas relações com seus pares, com a natureza, com a comunidade e tudo isso faz parte de um processo construído historicamente pelos próprios sujeitos que são agentes culturais, visto que "a cultura configura o mapa da própria possibilidade da vida social” (BRANDÃO, 2002, p. 24).

As manifestações da cultura do lugar estão imbricadas nos jeitos, nos modos de vida, nas relações de trabalho e se constituem pelos saberes produzidos ao longo de gerações e que são utilizados e reproduzidos pelas novas gerações conservando, de alguma forma, traços culturais de seus antepassados. Desse modo, a cultura passa a ser construída através das subjetividades dos sujeitos, através das experiências vivenciadas e dos valores compartilhados ao longo do tempo; assim, ela inexiste como algo que está posta, mas é algo que se constrói por sujeitos que vão se construindo e construindo seus modos de viver em uma sociedade, com características próprias. Concebemos o conceito de cultura de Geertz (1989, p. 15), quando diz que o homem é um animal amarrado a teias de significados que ele mesmo teceu de modo que também busca interpretá-la e dar um significado

Partindo desse conceito, buscamos entender como a cultura quilombola está sendo 'tecida' na comunidade do rio 
Baixo-Itacuruçá, via as representações e sentidos atribuídos pelas crianças que ali vivem e convivem.

Para a apreensão dos sentidos e significados sobre o ser quilombola nesse lugar sob o olhar das crianças, utilizamos dinâmicas de grupo junto a elas ${ }^{6}$ a partir da seguinte questão geradora: "o que sei sobre quilombola?". Da atividade percebemos que são crianças que gostam de desenhar, o que possibilitou a interação com a atividade proposta. A dinâmica se processou por meio de desenhos e textos escritos nos quais expressaram vários significados sobre a questão. A seguir, apresentamos alguns desenhos e escritos de alguns dos participantes:

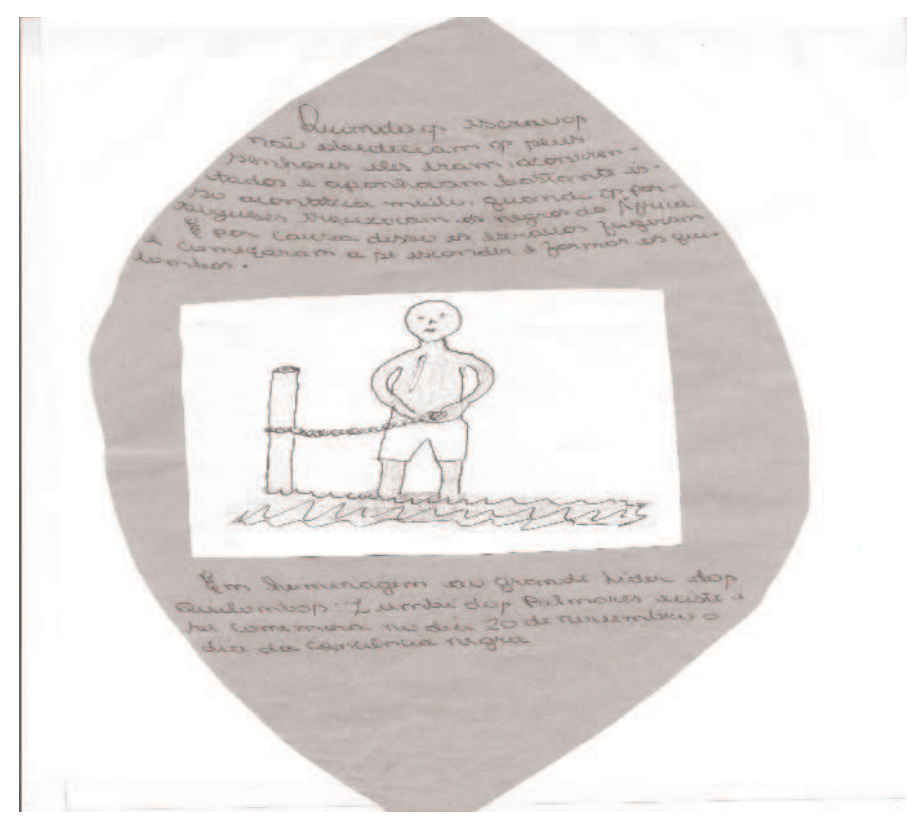

Nessa imagem, o aluno desenha e escreve o seguinte "quando os escravos não obedeciam aos seus senhores eles eram

6 A atividade foi realizada nas turmas de $5^{\circ}$ ano a $8^{\mathrm{a}}$ série na Escola Santo André. 
acorrentados e apanhavam bastante, isso acontecia muito quando os portugueses trouxeram os negros da África. E por causa disso os escravos fugiam e começaram a se esconder e formar os quilombos" (aluno ${ }^{7} \mathrm{~A}, 8^{\mathrm{a}}$ série)

Percebe-se que o aluno tem conhecimento de como se deu a formação dos quilombos no país, da história da escravidão que perdurou por anos e as marcas na vida das pessoas. Ainda sobre o ser quilombola outra aluna escreve o que aprendeu na escola, diz ela:

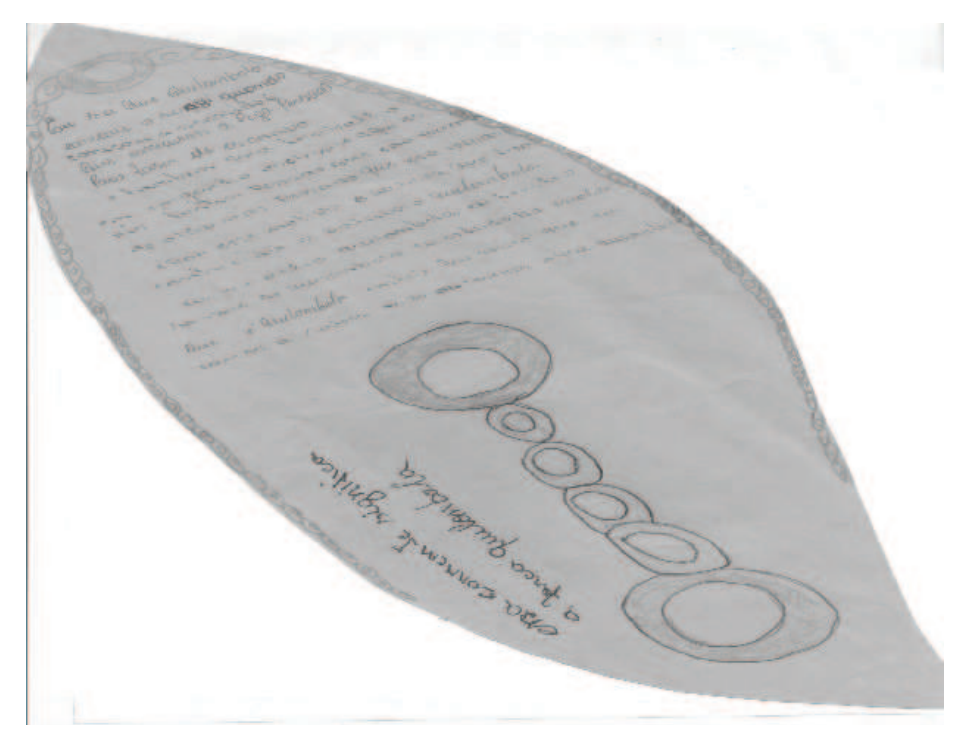

Eu sei que quilombola começou a surgir quando começou a escravidão que começaram a pegar pessoas pra fazer de escravos e também pra trabalhar em engenho. Inclusive aqui no rio, tinha pessoas que eram parentes de algumas pessoas que eram escravos, e por esse motivo ficou conhecida a palavra quilombola. Eu

7 Fizemos a opção pelo anonimato das crianças, utilizando letras para sua identificação.

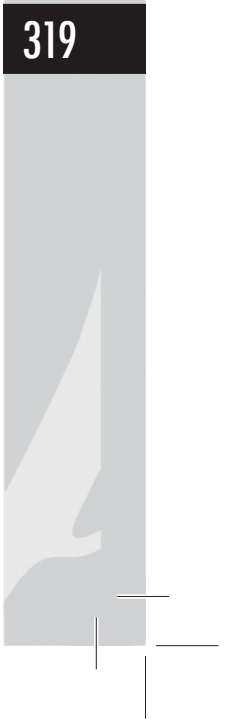


me acho quilombola, eu tenho sangue de quilombola, eu estudo na escola que é quilombola então, foi assim que eu comecei a saber mais ou menos o que é quilombola. (Aluna B, 8 a série)

Continuando com os escritos obtivemos:

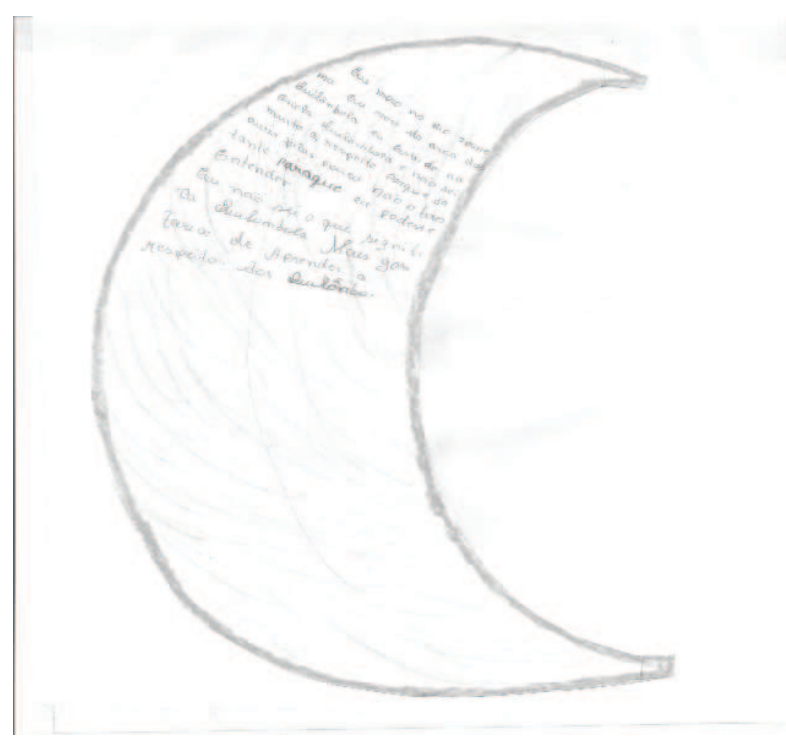

Eu moro no rio Ipanema, sou da área quilombola, estudo na escola quilombola. Não sei muito a respeito, porque já ouvir falar pouco, não o bastante para que eu pudesse entender. Eu gostaria de saber, não sei o que significa quilombola, mas gostaria de aprender a respeito dos quilombolas. (Aluna $C$, $8^{a}$ série)

Ouvir dizer que o quilombola é muito legal e divertido etc. (Aluno D, $6^{\circ}$ ano)

Morar em território quilombola, afirmar que estudam em escola quilombola, que há histórias de negros sendo discutidos no lugar, entre outros aspectos do diverso 'ser quilombola' é um assunto que circunda o cotidiano da sala de aula e da escola, de forma geral, embora o assunto não seja tratado em profundidade, 
talvez por isso os alunos retratem o 'acaso', o 'talvez', o 'eu sei pouco' quando são interpelados.

Seu modo de viver está marcado pela relação com a natureza e por modos culturais de imbricação do trabalhobrincar, foco que buscamos adentrar através das observações, de interlocuções com as crianças em momentos de brincadeiras, que perpassam por manifestações sociais, culturais e históricas.

Destaca-se que as manifestações culturais das crianças estão situadas pelo modo próprio, o brincar. Segundo Silva (2012), a brincadeira é uma manifestação cultural, social e histórica, que faz parte da vida das pessoas, e que na nossa cultura está muito vinculada ao mundo da criança. Quando a criança brinca constrói um universo próprio, e esse universo reflete o contexto no qual ela convive e interage. Nesse sentido, a brincadeira vai além do que costumamos ouvir, que a brincadeira faz parte do desenvolvimento humano, versão situada pela Psicologia, substituindo por uma visão mais ampla, pela dimensão cultural, na qual entendemos o brincar com a produção da cultura sendo "um conjunto de significações produzidas pelo homem" (BOUGÈRE, 2004, p. 8)

Nessa mesma perspectiva, pensar as manifestações culturais de um povo requer ir além do que geralmente entendemos como cultura, por exemplo, as danças, as lendas, os mitos, ou seja, o folclore em geral, o que segundo Brandão (2002, p. 116), significa "compreendê-la através da relação entre os processos de sua produção e seu próprio poder de processar como significado a vida social em todas as suas dimensões". Significa pensá-la como representação sobre um modo de vida e as experiências pessoais, exigindo aprofundar a compreensão do cotidiano em que ocorrem as peculiaridades. Tais peculiaridades passam por situar o lugar, o trabalho, as relações com seus pares, as brincadeiras, os tempos e os valores entre outros, aspectos que envolvem a vida humana.

Buscando entender como essas peculiaridades se manifestam na cultura quilombola do rio Baixo-Itacuruçá sob o olhar das crianças, primeiro foi preciso conhecer como se desenvolve a vida naquele lugar, como é a relação das crianças

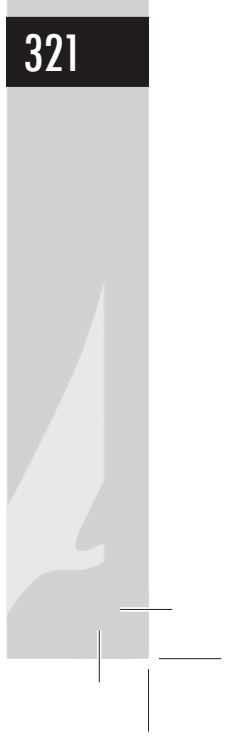


com os adultos, com o trabalho, com o rio, com a terra/ natureza, com a escola e, sobretudo, como se processam as brincadeiras das crianças, pois entendemos que ao brincar elas revelam conteúdos da vida que aprenderam da cultura adulta, da cultura do lugar, da cultura que chega, entre outras formas que nos escapam do 'olhar'.

\section{AS BRINCADEIRAS NO RIO BAIXO-ITACURUÇÁ}

Durante a travessia ${ }^{8}$ até a comunidade, passamos por várias comunidades ribeirinhas e quilombolas e, em volta do percurso, dentro de uma rabeta aberta que permite visualizar a paisagem verde da natureza, os rios e suas águas, observamos também crianças tomando banho e se divertindo no rio, outras remando em canoas descontraidamente, outras diante de suas casas conversando com seus pais, vimos algumas trabalhando nas olarias e há tantas outras brincando nos quintais de suas casas.

Naquela comunidade, a vida das crianças não é diferente de outros lugares, passa pela convivência com a família, nos afazeres de casa e da roça, há o tempo da escola e da brincadeira. Muitas crianças, principalmente as que estão em situação de vulnerabilidade social, passam mais tempo na escola, pois num horário participam de programas e projetos ${ }^{9}$ e, no outro tempo, participam do ensino regular. Sobre isso, eis o relato de uma criança, retratando sua rotina diária:

8 No decorrer da pesquisa foram feitas várias andanças à comunidade num percurso ora pelo rio, ora pela mata, caminhos das roças e ainda, passamos pelos arredores das residências dos moradores visando o reconhecimento do lugar, seus modos de vida e também para a coleta de dados. Outra forma de interlocução com a comunidade foi por meio da participação nos eventos festivos da escola e na audiência pública que tratou dos problemas físicos, estruturais e pedagógicos da escola.

9 Estamos nos referindo ao PETI - Programa de Erradicação do Trabalho Infantil e ao Programa Mais Educação do Governo Federal. 
escovo os dentes, bebo café, me arrumo e vou pra escola estudar no PETI e, de tarde, eu tomo outro banho, almoço e vou estudar normal (...) encho água pra mamãe, capino o terreiro pra ela (...). Na roça quando nós vamo (vamos) nós ajuda a mãe da gente com o pai.

Essa atitude relacional do trabalho e as crianças na comunidade não se constituem como exploração do trabalho infantil, mas um aprendizado laboral da rotina campesina, somado a escola e dessa forma não deixam de ir à escola por conta do trabalho e, segundo relato de uma mãe, as atividades que as crianças desenvolvem são simples, "eles fazem mais, é ajuntar a mandioca, quando tem roça pra plantar, eles vão plantar fazendo um serviço mais leve" (D. Luzia, 2013)

Para o brincar, utilizam os espaços diversos como o campo de futebol, o rio, o quintal de casa, as árvores, as canoas, as trilhas ou caminhos, a casa do vizinho e os espaços abertos da escola. Os usos dos espaços, as interações e as formas de brincar corroboram para um viver saudável e aprendizagem coletiva. Nesse sentido,

a brincadeira como prática social possibilita à criança transformar sua realidade, exercitando o imaginário e suas habilidades, vivenciando cada brincadeira como unica, modificando o tempo, o espaço e os objetos desse brincar, (re)construindo e se (re)apropriando de suas práticas sociais. Assim, o brincar carrega as marcas da nossa vida: alegrias e tristezas, dores, angústias, sonhos, descobertas e realizações, que se expressam através da ludicidade. (SILVA, 2012, p. 26)

\section{3}

Observando o brincar das crianças, percebemos que as brincadeiras envolvem um número considerável de crianças, de modo que elas socializam e compartilham experiências com seus pares, aprendem reciprocamente as brincadeiras e suas regras, formam grupos diversos e plurais, na maioria das vezes há meninos e meninas, os maiores ensinam os mais novos e o brincar flui naturalmente. Segundo Carvalho (apud SILVA), 
As crianças compreendem o mundo na experiência da brincadeira e o fazem na interação com as outras crianças e com os adultos. Nessa interação a criança compreende o mundo, experimenta suas emoções e elabora suas experiências. (2012, p. 83)

As crianças desse rio têm uma relação estreita com os adultos, seja por conta do convívio em relação ao trabalho, o que possibilita uma vasta troca de experiências entre esses. $\mathrm{O}$ adulto serve de 'referência' para as crianças, pois a mesma ver nos seus pais, avós, tios, nas pessoas mais velhas, um aprendizado que a cada dia se desenvolve e contribui para sua formação social, assim como as crianças trazem elementos novos para os adultos como, por exemplo, falam do cotidiano da escola, muitas vezes alheio aos pais. Essas trocas de experiências vão desde uma conversa sobre o cotidiano até as técnicas adquiridas ao longo dos anos, por exemplo, de fazer farinha. Os adultos de hoje aprenderam com seus pais, e as crianças, ali observando e praticando um fazer, de certa forma vão aprendendo aquele modo de ser e estar no lugar. Assim, pensar a infância significa pensar como a sociedade a situa no mundo, suas interações e práticas sociais, que valores culturais estão imbuídos no mundo do brincar, do inventar e do imaginar.

Segundo Carvalho (apud SILVA, 2012), no exercício da brincadeira, a criança ensaia papéis, apreende valores, constrói formas de sociabilidade, adquire motivação e habilidades necessárias a sua convivência social, ao mesmo tempo em que se projeta nas atividades adultas e as práticas culturais de que participa. Em síntese, a criança aprende a brincar com as pessoas que fazem parte de seu contexto social e cultural, permeado por hábitos e valores de grupo social, o que é construído e reconstruído processualmente.

Ao conversarmos com um menino ${ }^{10}$ de dez anos, morador

10 As entrevistas aconteceram para compor o Trabalho de Conclusão de Curso (TCC) ocorrido no período de março a junho de 2013, com crianças das 
da comunidade, sobre com quem aprendeu as brincadeiras, ele responde: “(...) vendo os outros brincarem (...)" outras pessoas (adultos) e outras crianças. Nota-se que não há uma receita pronta para se brincar, se faz na ação da própria criança pela possibilidade de troca e interação entre si em seu convívio e nos diversos espaços.

$\mathrm{Na}$ sequência, realizamos o mapeamento do brincar junto às crianças desenvolvido em duas sessões de brincadeiras, buscando interagir com o grupo de crianças na expectativa de apreensão acerca de aspectos culturais, estéticos e valorativos expressados por meio dessa ação que revelam traços da cultura. Na primeira sessão, houve a brincadeira do 'formô' ${ }^{11} \mathrm{e}$, na segunda sessão, procedeu-se à brincadeira 'escravos de Jó. Através das brincadeiras houve interação e diálogo entre os participantes, direcionado por alguns questionamentos: se conheciam ou não a brincadeira, com quem brincam e o nome das brincadeiras. As sessões compuseram oficinas e aconteceram no decorrer da pesquisa junto aos alunos da Escola Santo André, nas turmas de $5^{\circ}$ a $9^{\circ}$ ano. Dessa feita, as crianças elencaram suas brincadeiras preferidas, quais sejam: o formô, o fio ou pula corda, o futebol, a

turmas de $5^{\circ}$ a $9^{\circ}$ ano/09 da Escola Santo André. Quanto as brincadeiras foram desenvolvidas com aproximadamente 10 crianças na faixa etária entre dez a quatorze anos de idade de ambos os sexos.

11 Brincadeira que se desenvolve com um quadrado no chão dividido em quatro partes, há duas equipes ( $\mathrm{A}$ e $\mathrm{B}$ ). A equipe $\mathrm{B}$ que está de fora do quadrado deve tentar ultrapassar pelos três participantes da equipe A, que ficam posicionados um em cada linha do quadrado, e estes devem se movimentar somente em cima da linha horizontal, com exceção do primeiro que se movimentar tanto na linha horizontal quanto a linha vertical do meio do quadrado. A brincadeira começa quando o participante da equipe A, que está na primeira linha do quadrado grita: - Formô! Se pelos menos um dos participantes da equipe B conseguir ultrapassar e voltar por dentro do quadrado sem ser tocado pela equipe A, vence a brincadeira. Agora se pelo menos um da equipe $\mathrm{B}$ for tocado, eles mudam de posicionamento com a equipe $\mathrm{A}$. A equipe $\mathrm{A}$ vai para fora do quadrado, tentando ultrapassar e, a equipe B, fica na linha. 
bandeirinha, a queimada, o mata no meio, o pira esconde, o pira cola, a amarelinha e a pira alta, escolhidas por elas como as mais conhecidas e parte do repertório cotidiano do brincar.

Muitas dessas brincadeiras citadas já são conhecidas em vários contextos, porém a brincadeira do formô apresenta-se como uma brincadeira peculiar daquela comunidade. O formô consiste na demarcação de território onde cada integrante do grupo impede a invasão do seu território (quadrado) e o corpo se expressa por gingados parecidos com os da capoeira. Para melhorar a compreensão, descrevemos, em forma de diagrama, a organização da brincar formô, conforme a imagem.
B
B
B

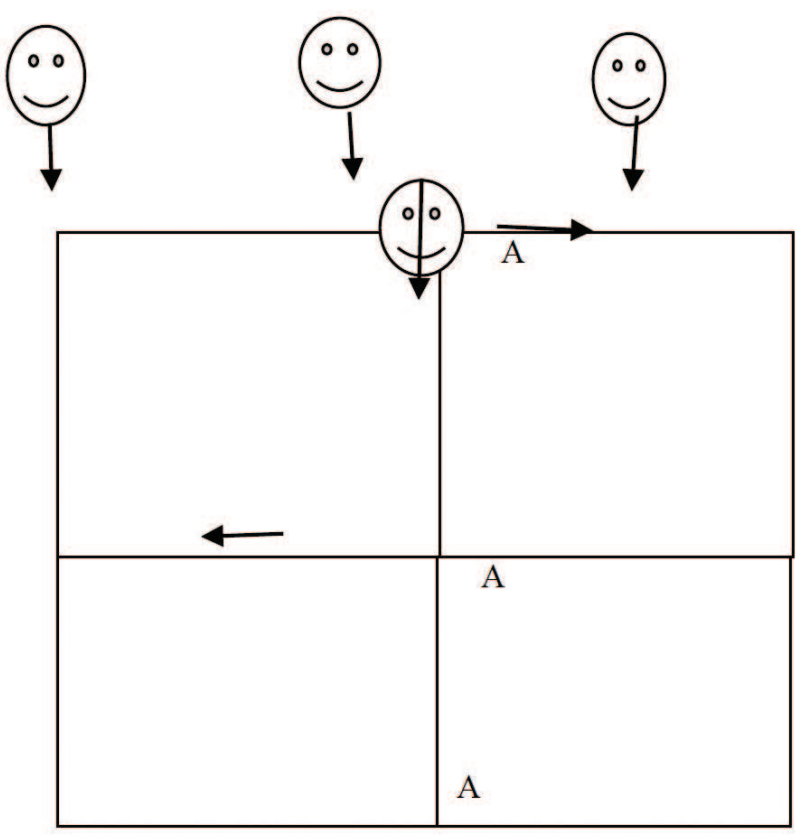

Nas observações durante as sessões de brincadeiras, percebemos que as crianças brincam juntas meninas e meninos; que as brincadeiras são desenvolvidas e organizadas por elas sem 
interferência do adulto; que não fazem distinção entre idades e interagem bem. Normalmente o brincar acontece no quintal das casas e quando elas não estão ocupadas com os pais e, quando se trata do espaço escolar, elas brincam no intervalo das aulas e somente na hora do recreio. O brincar como atividade das crianças tem restrição de tempo na escola, ficando silenciado se pensarmos o brincar como elemento cultural importante na formação do sujeito necessitando ser potencializado no currículo escolar.

Que traços culturais marcam essas brincadeiras? Pois as "brincadeiras são como rituais que se transmitem, repetidos ou recriados, em ambientes socioculturais distintos" (CARVALHO, 2011, p. 15).

Nas brincadeiras citadas, ficou explícito o corpo inteiro no jogo do brincar, a linguagem com palavreados próprios, a satisfação pela atividade, a harmonia da natureza imprimindo uma sonoridade para o brincar e, por isso, não gritam para serem ouvidos etc. Podemos observar a interação das crianças respeitando os tempos (da natureza, do trabalho dos pais, da escola) na relação com o brincar; a interatividade entre gerações com tranquilidade, reproduzida na obediência aos mais velhos advinda do convívio familiar e, ainda, que algumas brincadeiras são reorientadas pela dinâmica cultural existente seja por alguns modos próprios de falar, seja pela forma de lidar com o corpo (o gingado corporal), entre outros aspectos.

Portanto, a brincadeira é uma ferramenta de expressão, de aprendizagem, de cooperação e de representação da cultura. Como a pesquisa está em andamento consideramos que o olhar é diminuto quando se trata do cotidiano das crianças para um debate mais aprofundado.

\section{NOTAS PARA CONTINUAR A CONVERSA}

Destaca-se que a escola Santo André traz o título de $1^{\text {a }}$ escola Quilombola do município de Abaetetuba por ser oriunda das lutas dos movimentos sociais, em especial, dos moradores da comunidade e também da Associação dos Remanescentes de Quilombos de Abaetetuba (ARQUIA) quanto ao direito à 
educação dessas populações, em uma perspectiva de valorização da diversidade ética e cultural.

Essa luta por escola com a marca da negritude por si só tem relevância ímpar. Dito isso, consideramos importante destacar, com base nas observações realizadas, que em algum momento a escola precisa dar importância ao tema (o ser quilombola) visando contribuir com a aprendizagem dos alunos sobre a questão, visto que o tema se faz latente quando manifestam ou não o reconhecimento da raça, pelo conhecimento ou não da história do território onde moram e suas origens e porque alguns sentem o desejo de saber mais sobre esse diverso cultural. Assim a concretude do 'ser quilombola' é expressa no eu "já ouvir falar", afirmando o contraditório e plural de compreensão sobre o assunto. Os depoimentos situam:

Ser quilombola é um orgulho para mim, poisé um povo que lutou e conseguiu sair da escravidão e hoje tem vários descendentes. Mas eles deixaram a tradição de brincar, dançar e de pescar e etc. (Aluno E, $6^{\circ}$ ano)

Os negros fugiam porque eles trabalhavam tanto e não comiam, aí eles fugiram pra mata e encontraram um homem chamado Zumbi dos Palmares. Ele nasceu no dia nove de novembro de 1990. Daí surgiu um encontro de negros. (Aluno F, $6^{\circ}$ ano)

Quilombola para nós significa muito, porque antes as pessoas eram forçadas a trabalhar escravizadas, não se alimentavam bem, não recebiam pagamento pelo trabalho que faziam. E quando os escravos não queriam trabalhar eles eram presos e chicoteados $e$, às vezes, até morriam. Hoje as coisas mudaram muito porque nós, os descendentes de negros, podemos trabalhar livremente e ir para qualquer lugar. Para nós isso é muito bom. Hoje nós sentimos muito orgulho de ser quilombola. (Aluno G, $8^{a}$ série) 
As crianças conhecem a história de resistência e luta do povo quilombola, sabem como os escravos 'conquistaram' sua liberdade para que hoje seus descendentes sejam livres. E, da história contada e socializada fica que alguns se autorreconhecem, outros não, uns sentem vergonha da identificação, outros não se posicionam, ou seja, há um processo atual sendo construído na comunidade acerca do 'ser quilombola' num movimento vivo de fazer a história. Mais alguns depoimentos que nos ajudam a elucidar as informações e valores que estão sendo afirmados ou até negados sobre a história quilombola nesse lugar:

O que nós sabemos do quilombola é que é um lugar bonito e que tem pessoas muito boas na comunidade quilombola. São essas as nossas palavras. (Aluno H, $6^{\circ}$ ano)

Quilombola é uma comunidade do nosso planeta que envolve muitas pessoas e colabora com quem está doente. (Aluno I, $6^{\circ}$ ano)

Ser quilombola é uma comunidade muito popular, onde as pessoas se comunicam com outras pessoas de outra comunidade. (Aluna J, $6^{\circ}$ ano)

Chama atenção nos depoimentos acima o fato de que alguns alunos parecem não saber que as terras onde moram são de remanescente de quilombo, remetendo a um lugar distante e, por isso, talvez não se reconheçam como tal, ainda que a questão esteja no ar, na natureza, nas entrelinhas, em atos silenciados e também no pensar das pessoas que interagem com o lugar.

Fica o questionamento de como a escola se insere nessa história que vem sendo tecida pelos sujeitos do lugar.

Ademais para os participantes diretos da pesquisa que se colocam junto do lugar e dos sentidos de existência, fica a aprendizagem do atravessamento observando a sensibilidade humana dos sujeitos e seus modos de vida, visualizados na cooperação e no gostar de viver lá - no campo, apesar das muitas

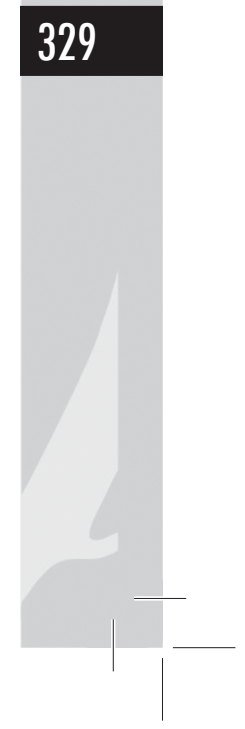


ausências, dado que "é o tempo da travessia: e, se não ousarmos fazê-la, teremos ficado, para sempre, à margem de nós mesmos" (PESSOA, 2013).

\section{REFERÊNCIAS}

BRANDÃO, Carlos Rodrigues. A educação como cultura. Campinas: Mercado de Letras, 2002.

BROUGÉRE, Gilles. Brinquedo e Cultura. Revisão técnica e versão brasileira adaptada por Gisela Wajskop. 5a ed. São Paulo: Cortez, 2004.

CARVALHO, Ana M. [et al.]. Brincadeira e Cultura: viajando pelo Brasil que brinca. Volume 1. São Paulo: Casa do Psicólogo, 2011.

GEERTZ, Clifford. A interpretação das culturas. São Paulo: Copyright, 1989.

OLIVEIRA, Ivanilde A. (org.) Cartografias Ribeirinhas: saberes e representações sobre práticas sociais cotidianas de alfabetizandos amazônidas. Belém: CCSE- UEPA, 2004.

PESSOA, F. Travessias. Disponível em: http://pensador.uol.com.br/ autor/fernando_pessoa. Acesso em: 20 maio 2013.

SILVA, Leonardo Toledo. As crianças e o brincar em suas práticas sociais: O aglomerado da Serra. Belo Horizonte: UFMG, 2012.

UFPA - Campus de Abaetetuba/GEPESEED. Projeto Integrando Conhecimentos e Saberes: uma experiência educativa na primeira escola quilombola de Abaetetuba/PA, 2013. (Digitalizado) 
COUTO, Luzia Diogo do. Entrevista concedida. Baixo Itacuruçá: Abaetetuba, 2013.

LOBATO, Clebson do Couto. Entrevista concedida. Baixo Itacuruçá: Abaetetuba, 2013.

PINHEIRO, Maria da Conceição Quaresma. Entrevista concedida. Baixo-Itacurucá: Abaetetuba, 2013.

SANTOS, Rinaldo Gomes dos. Entrevista concedida. Baixo Itacuruçá: Abaetetuba, 2013.

RODRIGUES, Lucindo. Entrevista concedida. Baixo Itacuruçá: Abaetetuba, 2013. 